\title{
PYOCELE OF THE ORBIT FOLLOWING FRACTURE OF THE MAXILLA*
}

\author{
BY
}

\author{
F. N. SHUTTLEWORTH AND P. F. KING \\ From Princess Mary's R.A.F. Hospital, Halton
}

THE following case is described because of its interest, and because no description of a similar case has been found in the literature either of ophthalmology or of otorhinolaryngology.

\section{CASE RePORT}

T.R.T., male aged 27 years, was seen at this hospital as an out-patient in August, 1950.

History.-He stated that for the past 3 years the left eye apparently turned upwards after he had been in a draught or when he had a cold. On these occasions he never saw double, although there was an obvious area of sclera showing above the left lower lid. On one occasion the condition was diagnosed as angioneurotic oedema, and treated with antihistamines with apparent success, although there was a subsequent relapse. In February, 1950, the condition recurred again, and the left eye became steadily more elevated. Enquiry was made as to the possibility of local trauma, and the patient revealed that in 1943 he received a kick in the left cheek while playing Rugby football, which resulted in a "black-eye " but no other ocular symptoms. In 1944, he was struck above the left eye by a flying discus. He had never correlated either accident with his ocular symptoms.

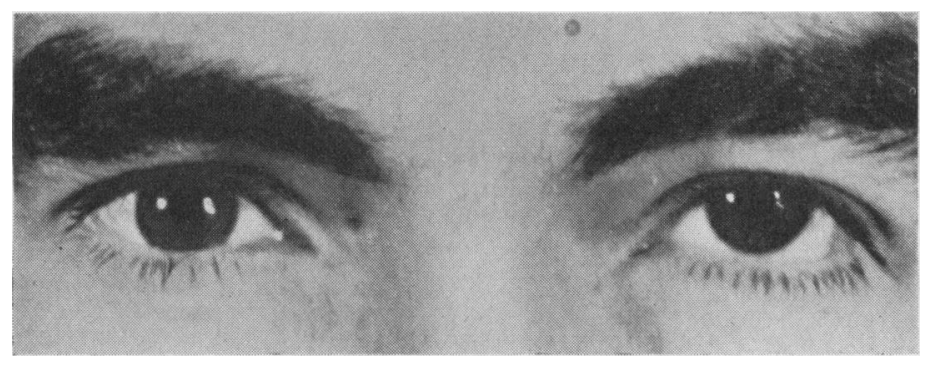

Fig. 1.-Left eye before operation.

Clinical Findings.-The first impression was one of left hypertropia, but examination showed the left eye to be raised almost $\downarrow$ in. above its fellow (Fig. 1). There was no

$$
\text { * Received for publication February 2, } 1951 .
$$


diplopia, ocular movements were full, the fundi were normal, and corrected vision right and left was 6/5. There was no proptosis. The left lacrimal sac was patent. The pupils were equal and both active.

Palpation of the left lower orbital margin disclosed a "step" in the middle third; a soft, smooth mass could be palpated in the floor of the orbit above the outer threequarters of the orbital rim. There was no depression of the left malar bone, and no anaesthesia in the distribution of the infra-orbital nerve. It was obvious that the eye was lifted by a tumour. Examination of the nose showed an allergic rhinitis, and no evidence of pus or polypi.

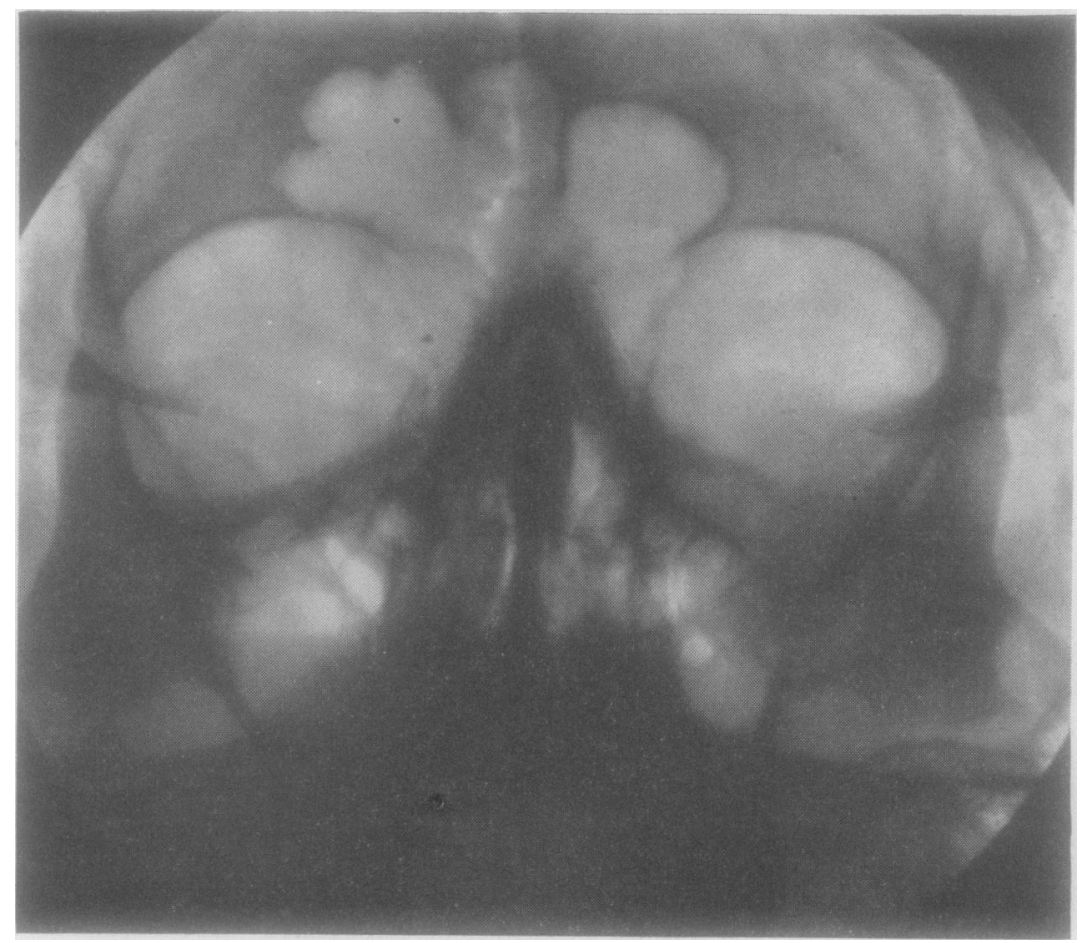

FIG. 2. - X ray of nasal sinuses.

X-ray Examination.-A radiograph of the nasal sinuses (Fig. 2) showed the following:

(1) Fluid level in right antrum.

(2) Markedly thickened lining membrane of upper outer angle, extending along roof of left antrum.

(3) Old fracture of floor of left orbit just lateral to infra-orbital foramen, with fracture of lateral wall of antrum, and some rotation of the body of the malar.

(4) Dim shadow in floor of left orbit. 


\section{Proof Punctures of Antra}

$$
\begin{array}{lllll}
\text { Left } & \ldots & \ldots & \ldots & \text { Clear } \\
\text { Right } & \ldots & \ldots & \ldots & \text { Clear straw-coloured fluid. }
\end{array}
$$

Diagnosis.-In view of the history and clinical findings, the diagnosis was made of mucocele of orbit, secondary to fracture of left maxilla, the fracture of the maxilla having no doubt occurred in 1943.

Operation.- It was decided to attempt removal of the mucocele, and as a preliminary step, in order to determine the state of affairs inside the antrum, a left Caldwell-Luc antrostomy was performed under general anaesthesia on October 23, 1950. At operation, a well-defined fracture line in the lateral wall of the antrum was well demonstrated. The lining mucosa of the antrum was oedematous and not unduly thickened, there were no polypi and the lining membrane showed complete continuity over the fracture line in the roof of the antrum. Convalescence was uneventful.

Exploration of the left orbit under general anaesthesia was undertaken on November 2, 1950, with a view to excising the mucocele. A skin incision was made as the approach was of necessity extra-conjunctival. After splitting the orbicularis, the mucocele was soon disclosed as a long, flattened, greenish grey "grape". The periosteum of the orbital floor was so lifted by the mass that it was divided with the periorbita, and separation at the orbital margin was unnecessary. The mucocele had an extremely thin wall; eventually this was ruptured during blunt dissection, and a quantity of thin mucus and some thick yellow pus was sucked away. Separation was continued towards the apex of the orbit; and beyond the beginning of the infra-orbital canal in the lateral wall of the inferior orbital fissure this became increasingly difficult. The mucocele was finally removed, a small remnant of its wall being left towards the apex of the orbit. The orbit was insufflated with penicillin powder, the periorbita was sutured with catgut and the skin with a subcuticular stitch. A short course of intramuscular penicillin was given post-operatively.

Bacteriological Examination.-The pus in the mucocele contained Streptococcus viridans.

Histological Examination.-The mucocele was lined by cuboidal epithelium with a lymphocytic infiltration of a moderate degree in the wall and surrounding connective tissue. There was no evidence of an acute suppurative process.

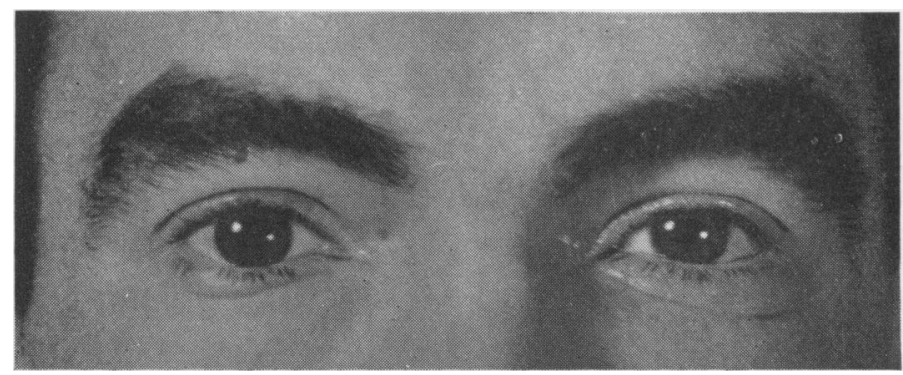

FIG. 3.- - Left eye after operation.

Result.-The position and mobility of the eye returned to normal in a fortnight (Fig. 3). 


\section{COMMENT}

A case of pyocele of the orbit after a minor fracture of the orbit is described.

It is thought that the original mucocele in this case could have arisen in one of two ways:

(1) By prolapse of the antral mucosa through the un-united orbital fracture; the mucosa, having an allergic character, became polypoid and irreducible through the fracture line.

(2) By partial detachment into the orbit of a piece of antral mucoperiosteum at the time of the accident, with subsequent cyst formation.

The correct aetiology being unknown, it was necessary to explore the antrum before excision of the mucocele could be attempted. As later events showed, the mucocele had in' fact arisen by detachment of a piece of antral mucoperiosteum.

\section{SUMMARY}

A case of pyocele of the orbit and its surgical removal are described. The original mucocele was traumatic in origin and undoubtedly of 6 or 7 years' duration. It was symptom free. Presenting signs were cosmetic, namely elevation of the eye and the appearance of vertical squint.

We wish to thank the Director General of Medical Services, and the Consultants in Ophthalmology and Otorhinolaryngology, Royal Air Force, for permission to publish this case. 